\title{
BURNS AND SCALDS
}

\author{
C J Hobbs
}

\section{Accident - lapse in usual protection given to the child \\ Neglect - inadequate or negligent parenting, failing to protect the child \\ Abuse - deliberately inflicted injury}

Accidental burns and scalds in children occur because of a lapse in the usual protection given to the child. Neglected children may be burnt because of inadequate or negligent parenting, which is a failure to protect the child, whereas in abused children burns and scalds are deliberately inflicted.

Burns and scalds within the range of child abuse are seen as serious injuries, as sadistic and linked with the sexual or violent arousal of an adult, and as punitive to evoke fear ("I'll teach him a lesson").

\section{Prevalence}

Deliberately inflicted burns and scalds are Left: Contact burns in 2 year retardation who was abused by his mother. Burns to penis were also present. Right: End of curtain wire heated in fire that was responsible for burns
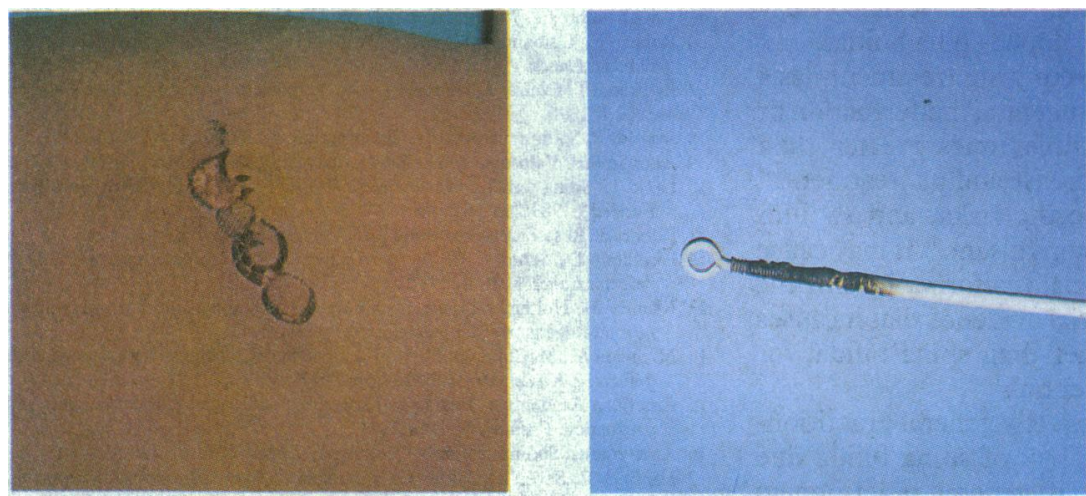

Cratered deep cigarette burn in typical site on back of hand in 5 year old boy, who also said, "Mummy put her fingers in my bottom"

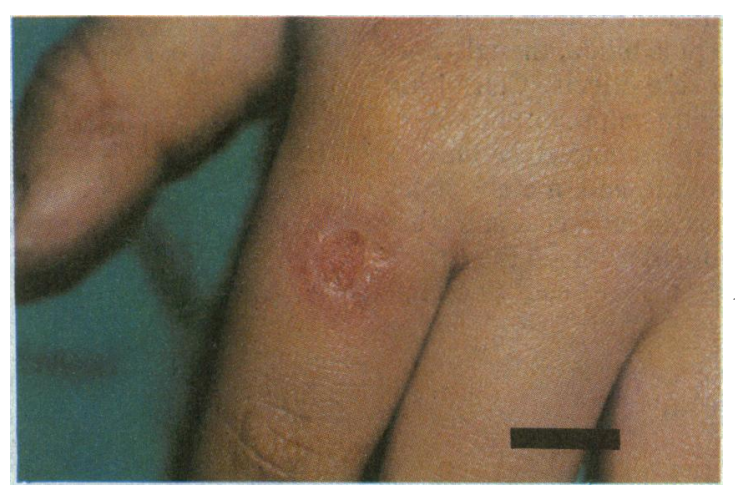

underrecognised and underreported because diagnosis may be difficult.

The peak age of children accidentally burning or scalding themselves is during the second year; the peak age of children being deliberately burnt is during the third year.

\section{Types of thermal injury}

Scalds-These are caused by hot water-for example, in drinks, liquid food, and baths. Scalds cause blisters and the affected skin peels in sheets and is soggy and blanched. They have a characteristic shape: they follow the contours of clothes and are enhanced by them, and drip, pour, and splash patterns are seen. The depth of injury is variable and contoured.

Contact, dry burns - Such burns are caused by hot objects, usually metallic, and electric fires. The injury looks like a brand mark, sharply demarcated and with the shape of the object that caused it. The burn is dry and tends to be of a uniform depth.

Burns from flames-These are caused by fires and matches and may be identified by charring and by singed hairs.

Cigarette burns - These leave a circular mark and a tail if the cigarette was brushed against the skin. In physical abuse the burn tends to form a crater and to scar because the injury is deep. The injury may be multiple but it is not particularly common.

Electrical burns - These are small but deep with exit and entry points.

Friction burns - These occur when, for example, a child is dragged across a floor. Bony prominences are affected and the blisters are broken.

Chemical burns - These may cause staining and scarring of the skin.

Radiant burns - These are caused by radiant energy - for example, from a fire or the sun. Injury is usually extensive and affects one aspect of an arm or leg or the body and is limited by clothing. The skin shows erythema and blistering. Such burns occur in children who are made to stand in front of a fire.

\section{Depth of burns and scalds}

The depth of burns depends on the temperature and time of exposure. At $44^{\circ} \mathrm{C}$ it takes 6-7 hours for full thickness destruction of the skin, at $70^{\circ} \mathrm{C}$ only 1 second, and at $60^{\circ} \mathrm{C}$ (the temperature of the hot water supply in many homes) about 10 seconds.

The other factor determining the depth of
Dr C J Hobbs, MRCP, is paediatrician at St James's University Hospital, Leeds. 
Friction burn in baby pulled across carpet by sibling

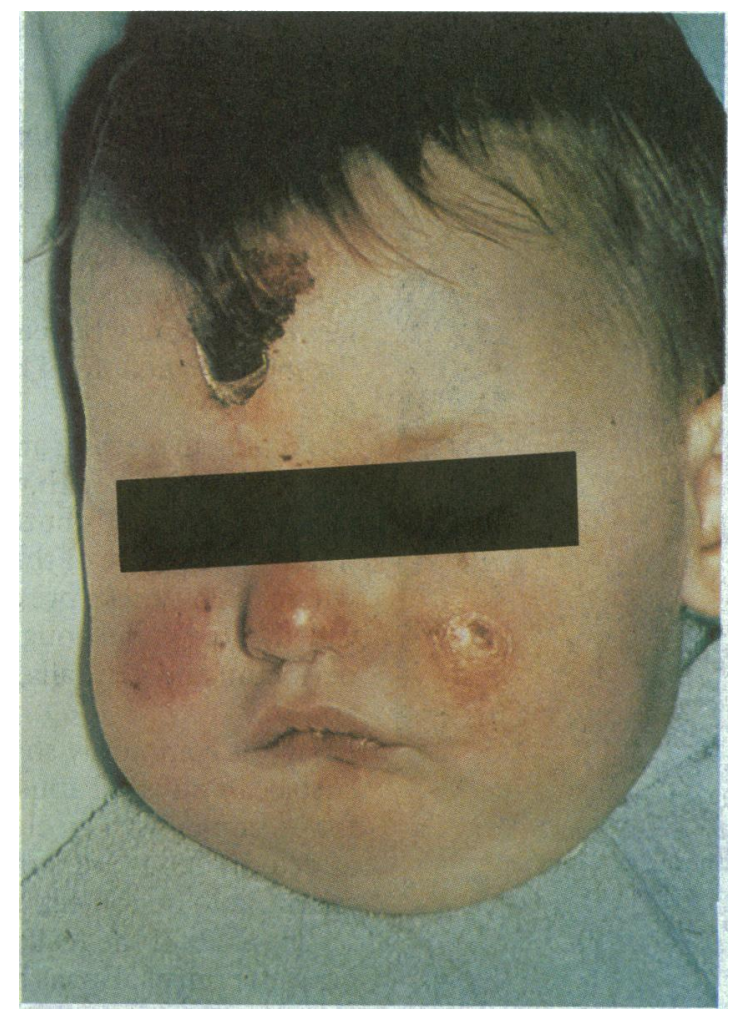

Examination of this 18 month old girl's older brother in school for an unexplained burn on his back led to chance discovery of these old, healing, partially infected contact burns for which parents had not sought treatment. The source was fire; both children had been abused

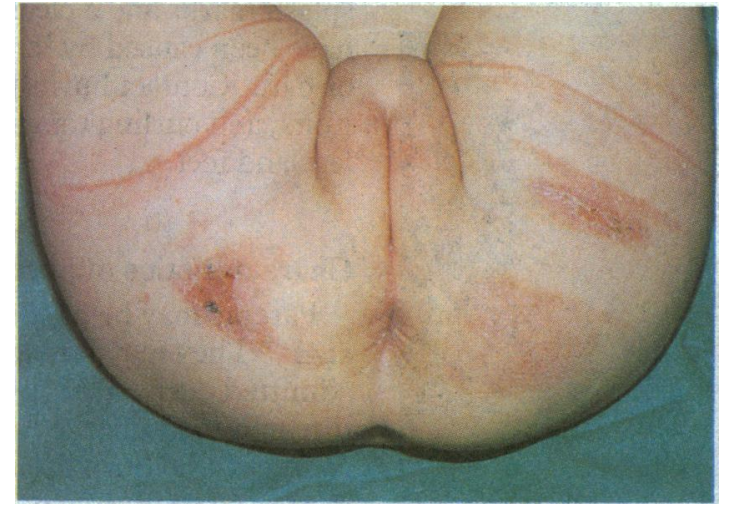

\section{Important sites and patterns}

Accidental burns

Most common scalds in toddlers and older infants occur when the child pulls kettles, pans, or cups of hot water or drinks from a kitchen unit or table. The scald affects the face, shoulders, upper arms, and upper trunk.

Accidental scalding from hot baths leaves an irregular mark with splashes.

Contact burns tend to be superficial, except in accidents with electric bar fires in which the hand
Left: Scalds from coffee thrown by drunken father at 3 year old girl producing scattered splash effect. Differentiation from accidental scalds from pouring liquids may be difficult

Right: Accidental scald typical of pulling kettle from work surface by flex. Burn is variable thickness and head and shoulders take brunt of injury

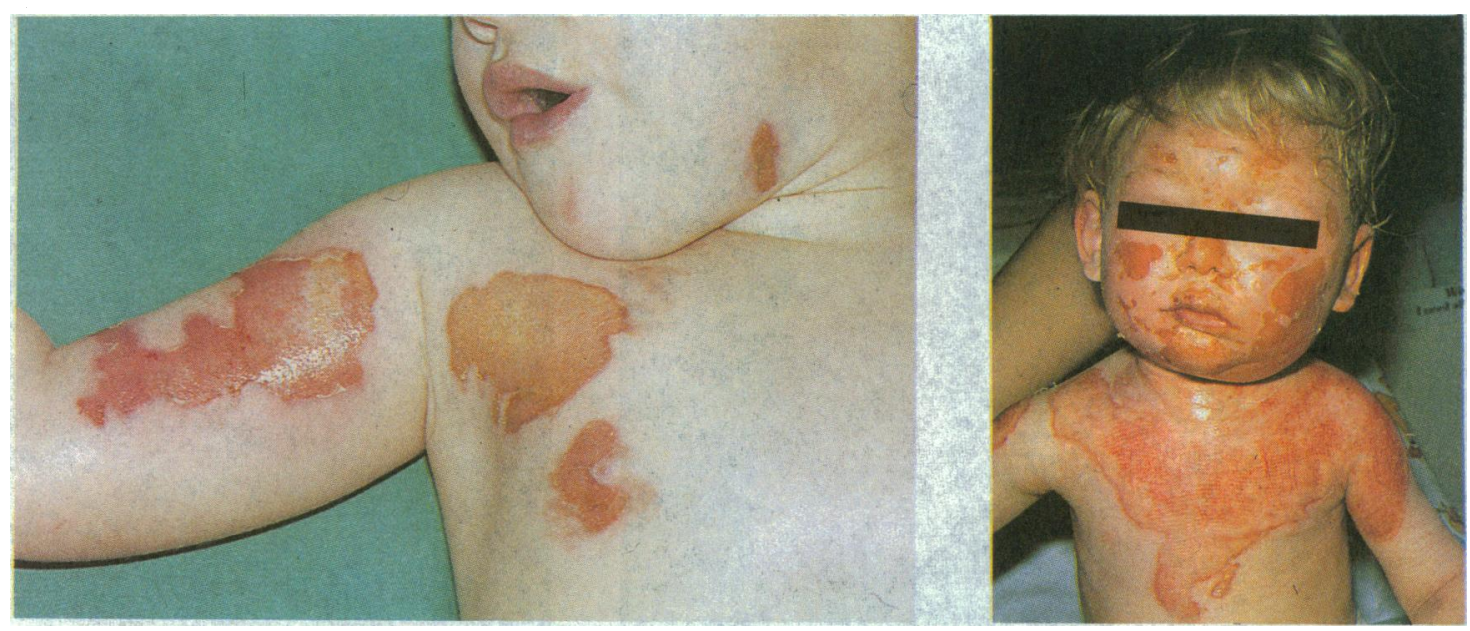




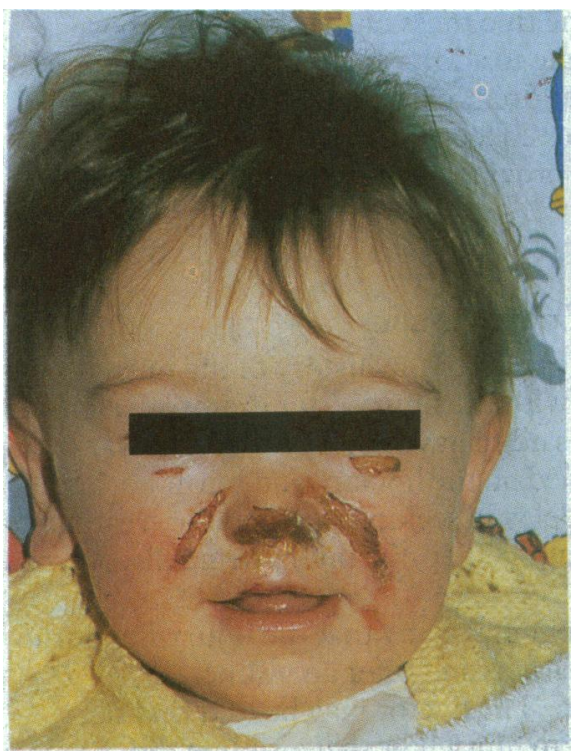

Food burns in 9 month old child with failure to thrive that allegedly occurred when he was left alone with bowl of hot food. Parents' refusal to allow admission to hospital, absence of burns in mouth, and failure to match burn with supplied utensil left serious doubts

Admitted abuse in boy aged 3 years. Hand was held under hot tap

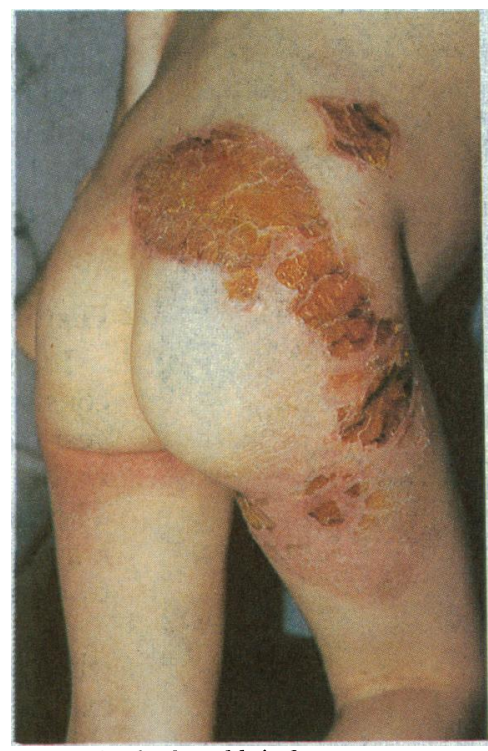

Extensive bath scalds in 3 year old girl failing to thrive.

Central part of buttock spared where pressed on to cool base of bath- "hole in doughnut" effect. Abuse suspected but unproved

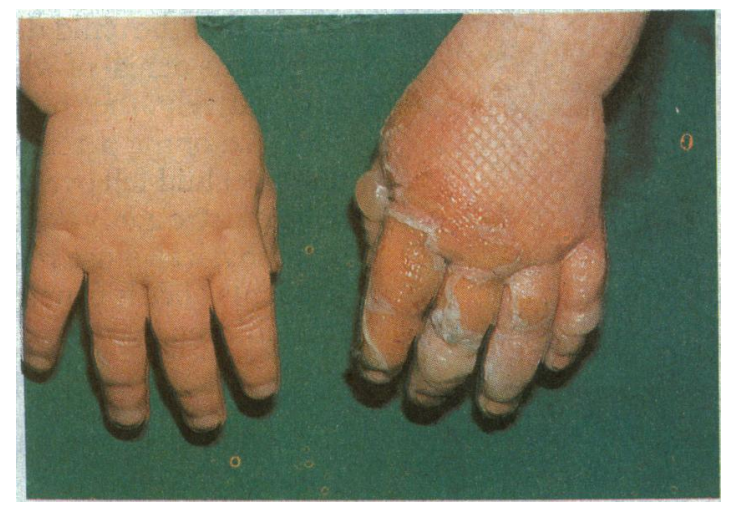

sticks to the bar and sustains deep destructive burns to the palm.

\section{Burns due to physical abuse}

Non-accidental burns affect the face and head, perineum, buttocks, and genitalia, the hands, and the feet and legs.

Cigarette burns may be seen on the face and head. Burns may be seen around rather than in the mouth where food has been pushed into the face.

To punish wetting and soiling misdemeanours or cure problems with wetting, abusing parents may dip the child's buttocks into a bath of hot water. The centre of the burn may show sparing where the buttocks pressed on to the bath - the so called "hole in the doughnut" effect. Burns to the perineum and genitalia may be part of sexual abuse.

Hands commonly show burns to the dorsal surface in physical abuse, whereas in accidents for example, with an electric fire - the palm is affected. Hands are burnt by being held under a tap or on to hot objects.

The soles of the feet may show contact or cigarette burns. Burns on the feet and ankles may show a stocking or glove distribution with no splash marks and a clear tide mark when they have been caused by forced immersion in a sink or bath. Contact burns from fires (grid marks), irons, and curling tongs may also be seen on the legs and feet.

\section{Characteristics of parents and children}

Parents may be hostile, abusive to staff, and angry. They may refuse to allow the child to be admitted despite the need for treatment or threaten to discharge the child prematurely. Mothers who burn their children may be depressed, withdrawn, seeking help, and be themselves victims of child abuse (often sexual abuse).

In contrast to parents of accidentally burnt children abusing parents may show a lack of concern for the child or a lack of guilt. Parents of accidentally burnt children are often defensive, guilty, and dislike being questioned about the

Boy aged 30 months with symmetrical stocking scalds (full thickness in part) to both feet and superficial scald to buttock with unaffected intervening areas. History of unwitnessed bathing accident but forced immersion later admitted
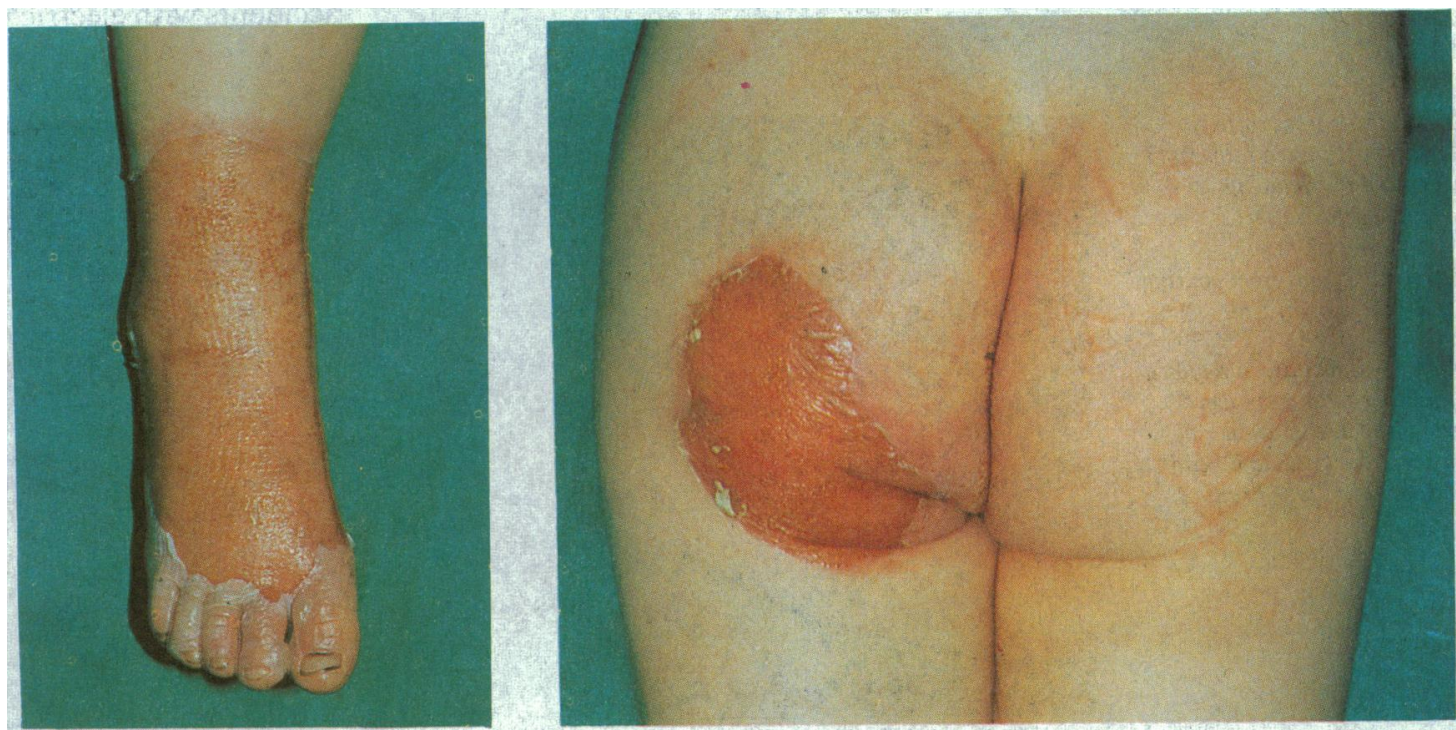
cause of the injury, which should not be misinterpreted as evidence of physical abuse.

A disturbed interaction between parent and child may show itself as anger and hostility towards the child - "It's his fault"-or as disregard of or an inability to cope with the child's behaviour. Abused children may be excessively withdrawn, passive, and uncomplaining about dressings or extremely anxious, hyperactive, angry, and rebellious, especially in the children's ward. In older children a reluctance to talk about their injury and how it occurred is worrying.

\section{Assessment}

Assessment is multidisciplinary and entails the participation of doctors (general practitioner, accident and emergency doctor, plastic surgeon, and consultant paediatrician), nurses, health visitors, social workers, police officers, and forensic scientists. In other words, the social services, the primary health care team, the hospital team, and the police need to liaise.

Visits to the child's home with the police may be required to inspect the bathroom, kitchen, fires, and household equipment.
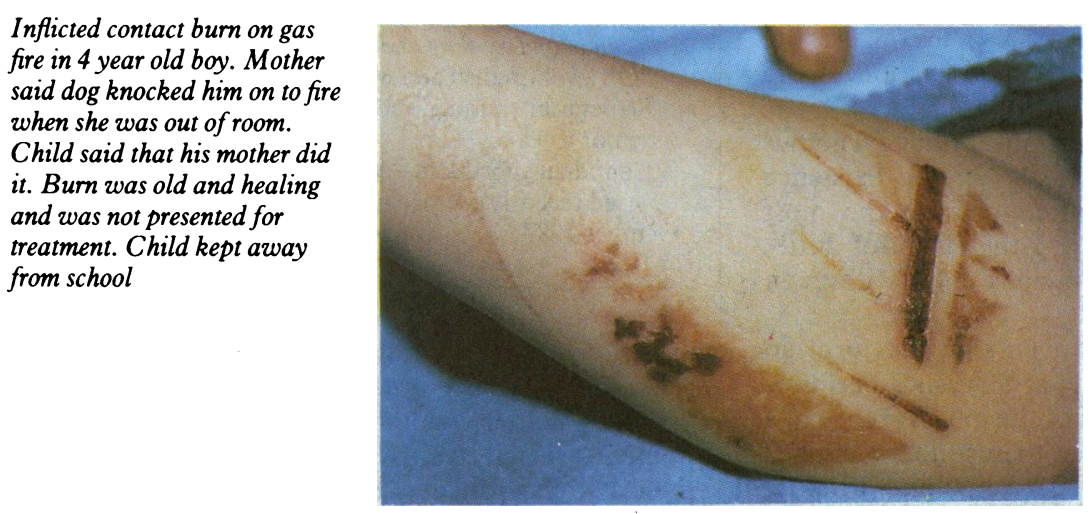

Partial thickness grid burn on back of wrist of 11 month old baby allegedly caused by older sibling. Mother later admitted responsibility for this single injury
History - This must be detailed and give the exact time of the incident, the sequence of events, and the action taken. Is the child's developmental ability consistent with what he is said to have done? For example, could an 18 month old child climb into a bath in the way stated?

Examination-Draw, measure, and photograph the injury. Manipulate the child's posture to discover his position when the injury occurred. Record the depth of the injury in relation to the temperature. Look for other injuries and look for signs of sexual abuse during genital and anal examinations. Assess the child's demeanour, behaviour, and development. In physical abuse a failure to thrive and a delay in acquiring language are common. Finally, always ask the child what happened.

\section{Differential diagnosis}

When there is a lesion and no history of a burn skin infection or disease should be considered. Examples of conditions that may mimic burns are epidermolysis bullosa, impetigo, papular urticaria, contact dermatitis, and severe nappy rash.

Improbable accidents can occur. For example, a child could be burnt by vinegar, as concentrated vinegar (glacial acetic acid) has a $\mathrm{pH}$ of $1 \cdot 6$. In addition, the buckles of seat belts or black vinyl seats heated by the sun have caused injuries that have been confused with physical abuse. In general central heating radiators are safe but hands have been badly burnt when they have been trapped behind one, and the injudicious use of hot water bottles for babies has resulted in burns that are caused by neglect rather than abuse.

Anaesthesia, an inability to move, or neurological deficit caused by a congenital insensitivity to pain, syringomyelia, spina bifida, mental disability, cerebral palsy, and epilepsy may be associated with unusual burns and scalds.

Neglect should also be considered. Children

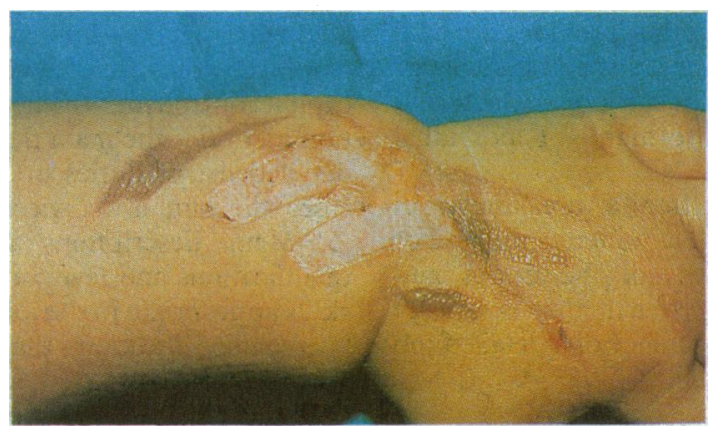

The ABC of Clinical Genetics will continue next week. The sixth article in this series, which has been edited by Professor Roy Meadow, will appear on 27 May. 